\title{
A Multidisciplinary Design Environment for Composite Rotor Blades
}

\author{
Peter J. Rohl ${ }^{1}$, Paul Dorman ${ }^{2}$ and Mark Sutton ${ }^{3}$ \\ Advatech Pacific, Inc., San Bernardino, CA 92408 \\ and \\ Devesh Kumar ${ }^{4}$ and Carlos E.S. Cesnik ${ }^{5}$ \\ University of Michigan, Ann Arbor, MI 48109
}

\begin{abstract}
Aeroelastic effects are significant design drivers in rotorcraft design. Typically, detailed structural information of the rotor blade necessary to determine its cross-sectional mass and stiffness properties is not available early on in the design process, especially for complex composite blades that are being employed in modern rotor systems. A 3D finite element (FE) approach does not easily lend itself to conceptual and preliminary design due to the effort required to create a 3D model and the associated run times for solving the FE problem. Classical 1D beam analysis of the rotor blade is fast and easy to use early in the design process, but does not take into account realistic cross-sectional properties of the blade, resulting in only low-fidelity aeroelastic models. Therefore, high-fidelity aeroelastic analysis is usually not done until late in the rotorcraft design process, when changes to the design are difficult and costly to implement.

The present work addresses this need for a design environment that combines the computational efficiency and speed of 1D beam analysis with high-fidelity accuracy approaching that of a 3D FE model. The environment contains a graphical modeling tool to rapidly define the cross sectional layup of a rotor blade or wing and a cross section mesh generator, both part of the IXGEN pre-processing tool. It uses a cross sectional beam analysis code (UM/VABS) to determine the cross sectional mass and stiffness properties, which it then feeds into a comprehensive rotorcraft analysis code (RCAS). Providing the option to use either DAKOTA or Phoenix ModelCenter as the optimization software, a full multidisciplinary design and optimization environment for the preliminary design of composite rotor blades and wings has been developed. As a test case, structural optimization case studies are presented where the cross-sectional layup of the blade is determined which results in significant vibration reduction at the rotor hub in forward flight conditions for the NASA/Army/MIT Active Twist Rotor (ATR) blade.
\end{abstract}

\section{Nomenclature}

$=$ thrust coefficient

$=$ Young's modulus

$=$ shear modulus

$=$ force

$=$ moment

\footnotetext{
${ }^{1}$ Engineering Manager, AIAA Senior Member.

${ }^{2}$ Aerospace Engineer.

${ }^{3}$ Aerospace Engineer.

${ }^{4}$ Graduate Research Assistant, AIAA Student Member.

${ }^{5}$ Professor, AIAA Fellow.
}

$$
\begin{array}{ll}
\Lambda & =\text { sweep angle } \\
\nu & =\text { Poisson's ratio } \\
\mu & =\text { advance ratio }
\end{array}
$$




\section{Introduction}

$\mathrm{T}$ HE design of composite rotor blades is inherently a multidisciplinary problem involving aerodynamics, static and dynamic loads, aeroelasticity, materials, life, manufacturing aspects etc. Each of these disciplines has its own high-fidelity analysis tools. A conceptual/preliminary design tool, however, has to strike the right balance between fidelity and computational cost since it is in the early design phases when a large portion of the design space needs to be explored. Therefore, a 3D finite element model of the rotor blade does not lend itself very well for structural analysis at this stage. Typically, a 1D beam model is employed instead. These (nonlinear) beam models have proven to be fully adequate if they are supplied with high fidelity mass and stiffness properties of the rotor blade. Since dynamics and aeroelasticity are key drivers of helicopter rotor design, low-fidelity mass and stiffness properties often lead to design problems that are not discovered until detail design, when they are very costly to fix. The work presented here addresses this shortcoming of the beam modeling approach to rotor blade design through coupling of the University of Michigan version of the Variational Asymptotic Beam Sectional analysis $(\mathrm{UM} / \mathrm{VABS})^{1,2}$ with RCAS, the Rotorcraft Comprehensive Analysis System ${ }^{3}$ in an integrated design environment. UM/VABS determines high-fidelity cross sectional properties for arbitrarily curved and twisted slender structures that are then used in a 1D beam finite element analysis, resulting in much higher-fidelity solutions for the beam problem without incurring the run-time penalties and complexity of a 3D solution. The $1 \mathrm{D}$ beam solution is produced by RCAS, which provides the loads and performance constraints for the blade design.

\section{Design Approach}

The basic approach to the rotor blade design problem is shown in Figure 1. The 3-dimensional design problem is subdivided into a $2 \mathrm{D}$ cross section and a $1 \mathrm{D}$ beam analysis problem ${ }^{4}$. The premise for this approach is that the artifact is slender, i.e. has a large length to width (and height) ratio, and it is somewhat uniform in the lengthwise direction, meaning one can find cross sections representative for regions of the artifact. Both premises are typically fulfilled for rotor blades.

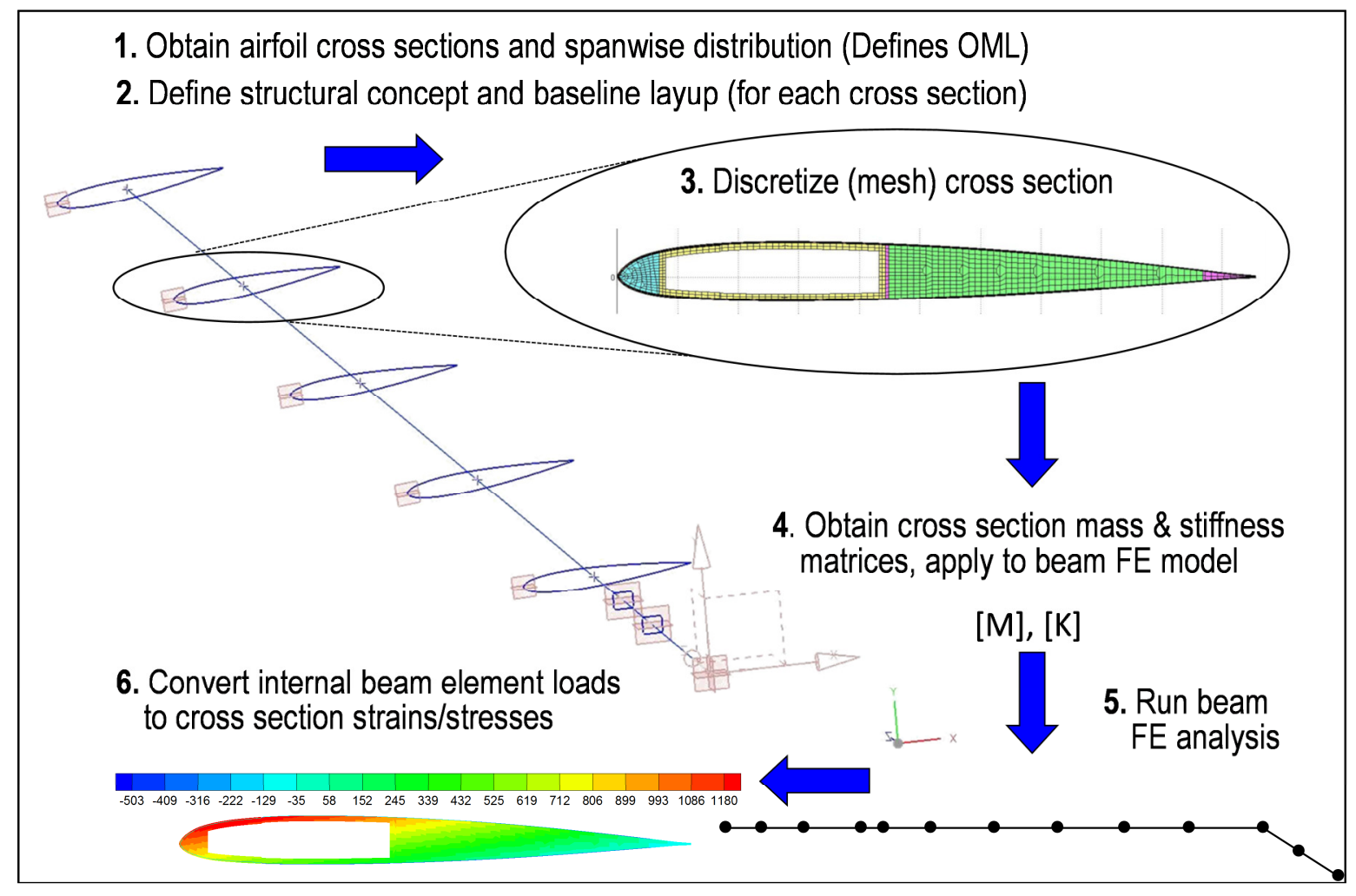

Figure 1. 2D - 1D Design Approach. 
Once the rotor blade is subdivided into its representative cross sections, each cross section is defined in terms of its structural topology, layout, materials and ply thicknesses (if applicable). It is then discretized (meshed), and $\mathrm{UM} / \mathrm{VABS}$ uses this mesh and material information to determine its mass and stiffness properties, shear center, centroid location and center of gravity. Both Euler-Bernoulli and Timoshenko (including transverse shear) beam theory is supported by UM/VABS, resulting in fully populated $4 \times 4$ or $6 \times 6$ mass and stiffness matrices, respectively. These mass and stiffness matrices are then assigned as properties to the corresponding beam elements in the 1D model. In a post-processing step, the element loads resulting from the dynamic or aeromechanical analysis are converted to equivalent stress and strain distributions in the individual cross sections.

Figure 2 shows the Multidisciplinary Design Optimization (MDO) process originally conceived at University of Michigan $^{5}$ that has been implemented in this work. The user interacts with the environment through a graphical user interface (GUI) where a rotor blade and its defining features are described and parameterized. Once a baseline rotor blade has been defined, an optimizer sets design variables defining the rotor blade and each of its representative cross sections. The parameterized rotor blade is generated by a modeling tool which contains a cross section mesh generator to create the input for the cross sectional analysis tool (UM/VABS). The mass/inertia and stiffness matrices for all representative blade cross sections determined by the cross sectional analysis tool are passed on to the aeromechanics code (RCAS) which calculates blade frequencies and loads (blade loads and hub loads, for example). In a post-processing step, the blade loads are used to perform a 3D stress/strain recovery operation to determine the stress and strain distribution in each cross section of the blade. These stress and strain values, together with output from the cross sectional analysis (location of the center of gravity and elastic axis in each cross section) and output from the aeromechanical analysis (blade frequencies, vibratory loads, hub loads) are used by the optimizer as constraint or objective values, respectively, in the particular optimization problem the user wants to solve. The optimizer loops around the entire process, changing the design variables, until its termination criteria are met (either the design converges to an optimum solution, or the optimizer reaches the maximum allowed number of iterations, for example).

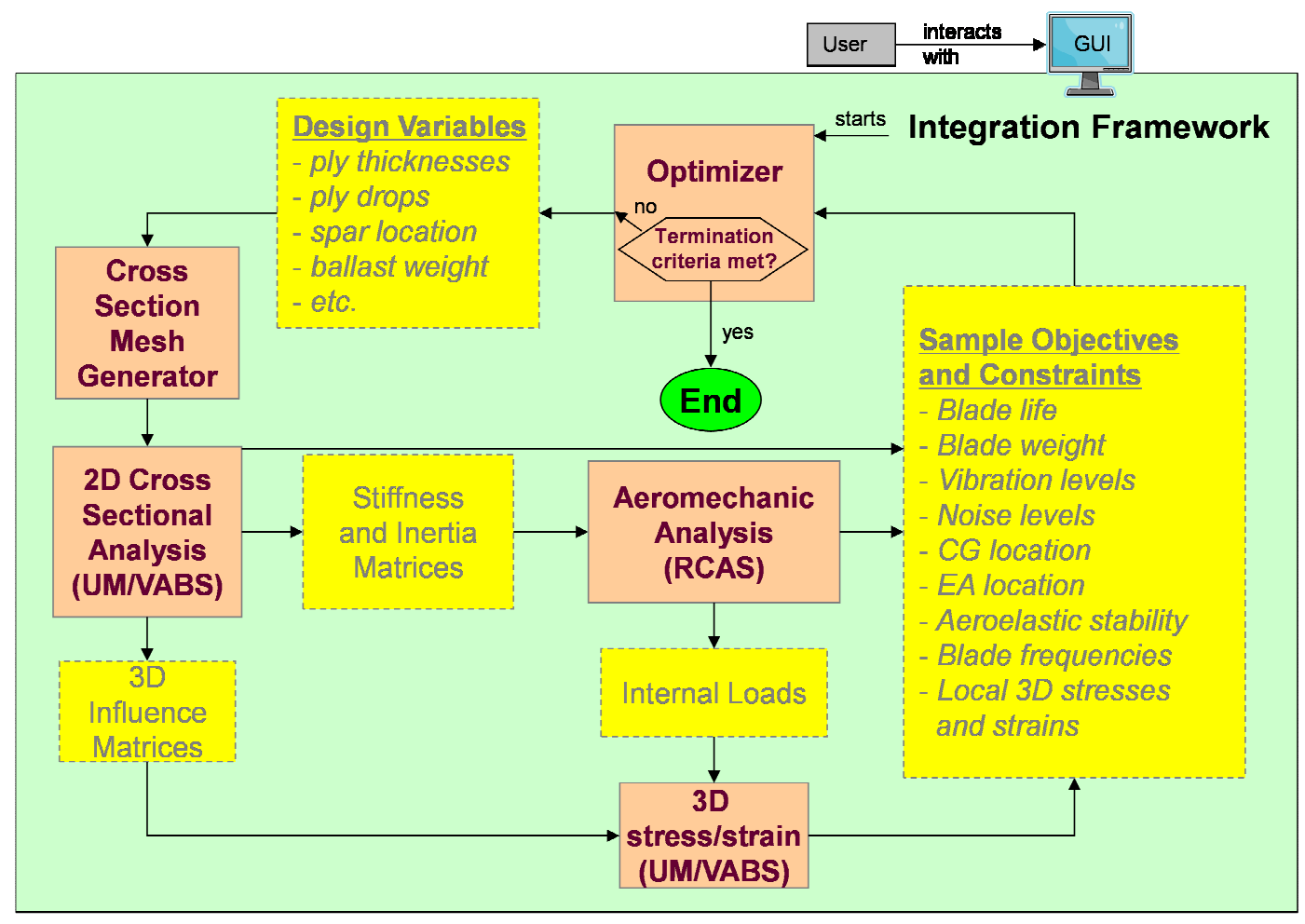

Figure 2. Multidisciplinary Optimization Process.

\section{MDO Environment}

The MDO environment developed in this work implements the process shown in Figure 2. The main piece of software developed in this project is IXGEN ${ }^{6}$, the parametric modeling environment for rotor blades. 


\section{A. Blade Modeling Tool IXGEN}

IXGEN is a rotor blade and slender wing modeling environment that lets the user quickly and easily define a rotor blade as a sequence of cross sections stacked in the spanwise direction along a user-defined stacking axis. IXGEN has two modes of operation - a GUI-driven mode for the designer to set up the blade, and a batch mode for use in an automated design framework, where an optimizer or other type of programmatic design driver modifies the defining parameters and regenerates the blade. IXGEN contains a mesh and UM/VABS model generator, and it has the ability to execute UM/VABS directly from the UI. However, it is significantly more capable than a mere mesh generator in that it abstracts the definition of a rotor blade and its cross sections to a higher, feature based level. These defining features, such as spar webs, spar caps, wrap layers, etc. are then parameterized, and these parameters, in turn, can then be driven by an optimizer or similar design driver.

Based on the design approach shown in Figure 1, IXGEN separates the rotor blade definition into a two-step process, that is a definition of each characteristic cross section of the blade with their topological layout (spars, wrap material, erosion protection, core fill etc.) and the positions of those cross sections in 3D space to make up the rotor blade. This includes the spanwise range for which each cross section is valid, blade twist, sweep, dihedral/droop etc. Each specific section airfoil is read from a file and is scaled by the local chord length. The cross section layout is defined parametrically so that the airfoil definition can be changed as part of the optimization process if desired.

IXGEN currently supports box, D and multi-cell spar concepts with spar webs either perpendicular to the defining airfoil chord or at a slant angle off perpendicular. Figure 3 shows several representative blade sections that have been modeled with IXGEN. While the tool was developed for helicopter rotor blade design, it has also been used to model typical wind turbine blade geometries.

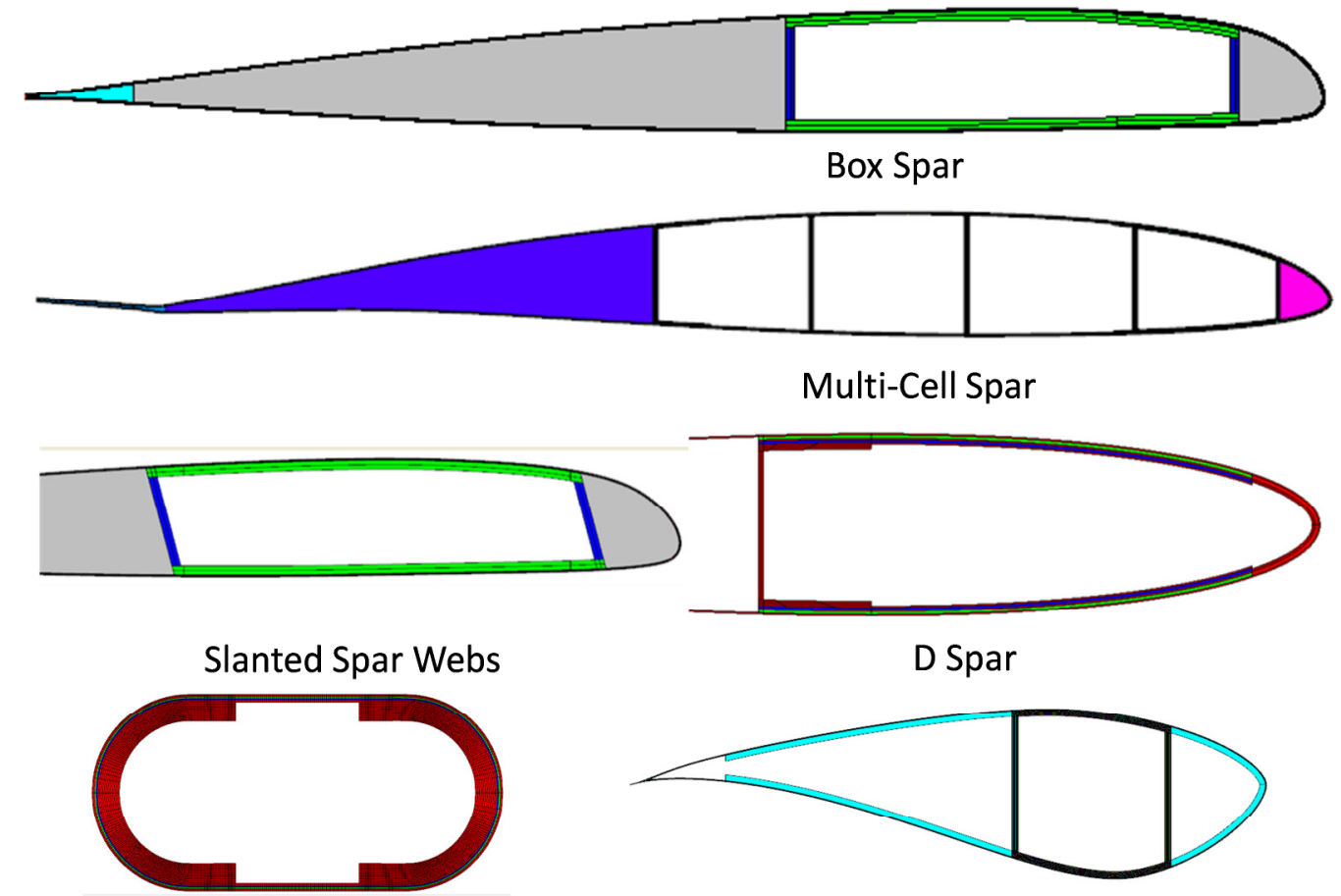

Blade Root Section

Typical Wind Turbine Cross Section

Figure 3. Representative Cross Sections Modeled by IXGEN.

Cross section properties are only determined at the spanwise positions of the defining cross sections. Properties are interpolated between those cross sections.

IXGEN is equipped with a 2D mesh generator which fully automatically creates a quadrilateral mesh meeting the requirements of UM/VABS in terms of node order and element connectivity. This is important for stress/strain recovery during post-processing. In interactive mode, the user has the ability to inspect the mesh and look at different mesh quality statistics. Figure 4 shows a quality check for maximum element angle with the red color indicating violation of the user-defined criterion. 
IXGEN contains a 3D geometry generator which generates:

- a 3D solid body for each material layer of each feature for each region,

- each cross section as a collection of 2D surfaces,

- each airfoil as a 2D spline,

- a collection of 3D surfaces representing the outer mold line (OML) and

- a piecewise linear axis representing the blade stacking axis.

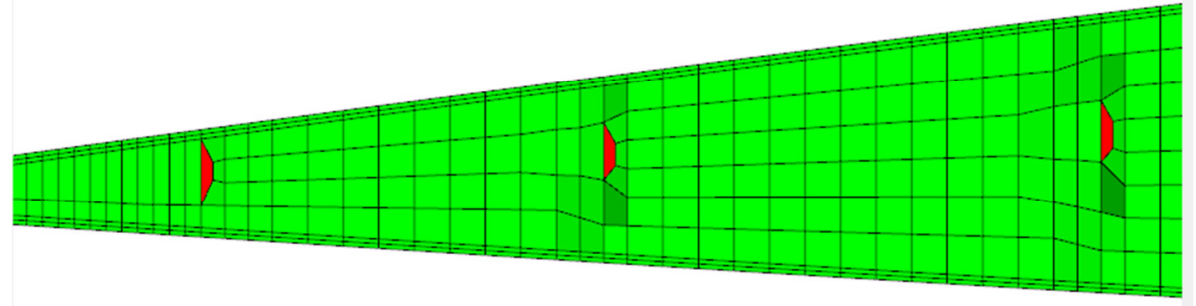

Figure 4: Mesh Quality Check.

The geometry display window of IXGEN is shown in Figure 5. Geometry (and therefore also blade twist) is linearly interpolated from the inboard to the outboard station of each design region. The geometry kernel used by the geometry generator (and also the 2D mesh generator) is OpenCascade $^{7}$, an open source geometry kernel. Export of STEP and IGES format is supported. The exported geometry
can then be imported into a full-fledged 3D CAD system such as CATIA or NX and used as a starting point by the product definition organization to generate a higher-fidelity blade model including 3D features like the transition from the blade root to the fully developed blade, and more realistic lofting in the spanwise direction.

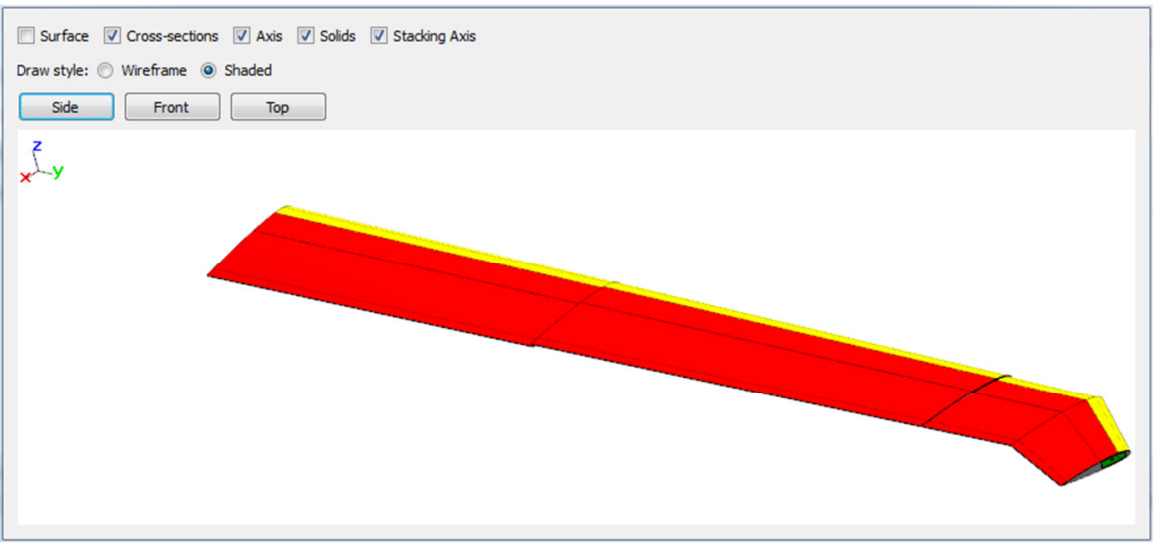

Figure 5. 3D Solid Geometry Model.
B. Optimization Interface Two separate optimization interfaces have been developed. One implements a tight integration with DAKOTA ${ }^{8}$, including a customized user interface briefly described below. This setup was used for the optimization work presented in reference 6 . It is easy to use and does not require a third-party software license. However, it does not offer the user full flexibility of changing the topology of the

optimization problem as does Phoenix ModelCenter ${ }^{9}$, which is loosely coupled with the IXGEN environment as an alternative optimization environment. ModelCenter is not just an optimization tool but a full integration framework. The ModelCenter-based setup was used for the application example presented in this work.

Any parameter used by IXGEN in the geometry parameterization can be linked to a design variable used by the optimizer. The inputs tab of the optimization interface is shown in Figure 6. The tree structure on the left expands down to each individual parameter used in the definition of the rotor blade. In the center panel, the user defines design variables and their bounds. The panels on the right show the blade parameters that are linked to each design variable. This easy-to-use linking scheme significantly reduces the size of the optimization problem and also makes it easy to enforce for example manufacturing constraints. For example let's assume one has a layer of plies that is intended to wrap around the box spar. One would link the thickness parameters of the corresponding spar web and spar cap layers to one thickness design variable to enforce constant ply thickness as shown in Figure 6.

Any response parameter produced by either UM/VABS or RCAS which is exposed by the MDO environment is available to the optimizer as either a constraint or objective value. Combination of multiple responses into an aggregate objective function is supported. Figure 7 shows the outputs tab of the DAKOTA interface. In a tree structure similar to the one used for the input parameters, all available output parameters are shown on the left. The 
user defines objective function and constrains by selecting response parameters on the left and inserting them either into the objective field or one of the constraint fields. By default, the optimizer minimizes, so that a negative sign is added for maximization as shown in Figure 7. Multiple individual objectives can be combined into an aggregate function using an arithmetic combination of objective values and weights. In the same fashion, the environment supports arithmetic in the formulation of the constraints. In the example in Figure 7, the constraint is normalized by its bound. The user can define additional response functions. These are merely tracked by the environment as the optimization progresses, so that they are easily available for post-processing. Once the user starts the optimization, the "Results" tab of the GUI is displayed, which shows a table displaying all input and output variables by iteration. After the optimization is complete, this table can be saved as a csv file for post-processing, for example in MS Excel.

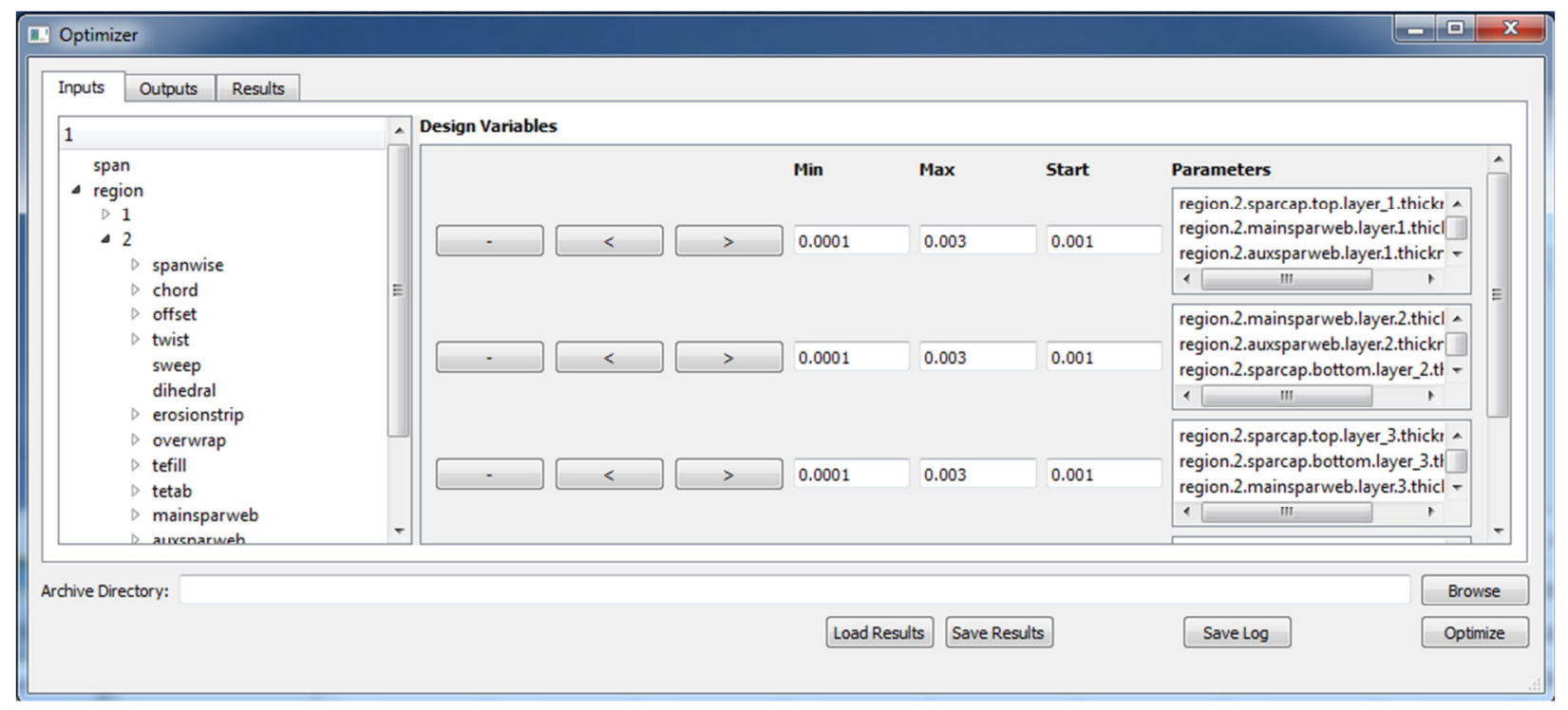

Figure 6. Optimization Interface (Inputs).

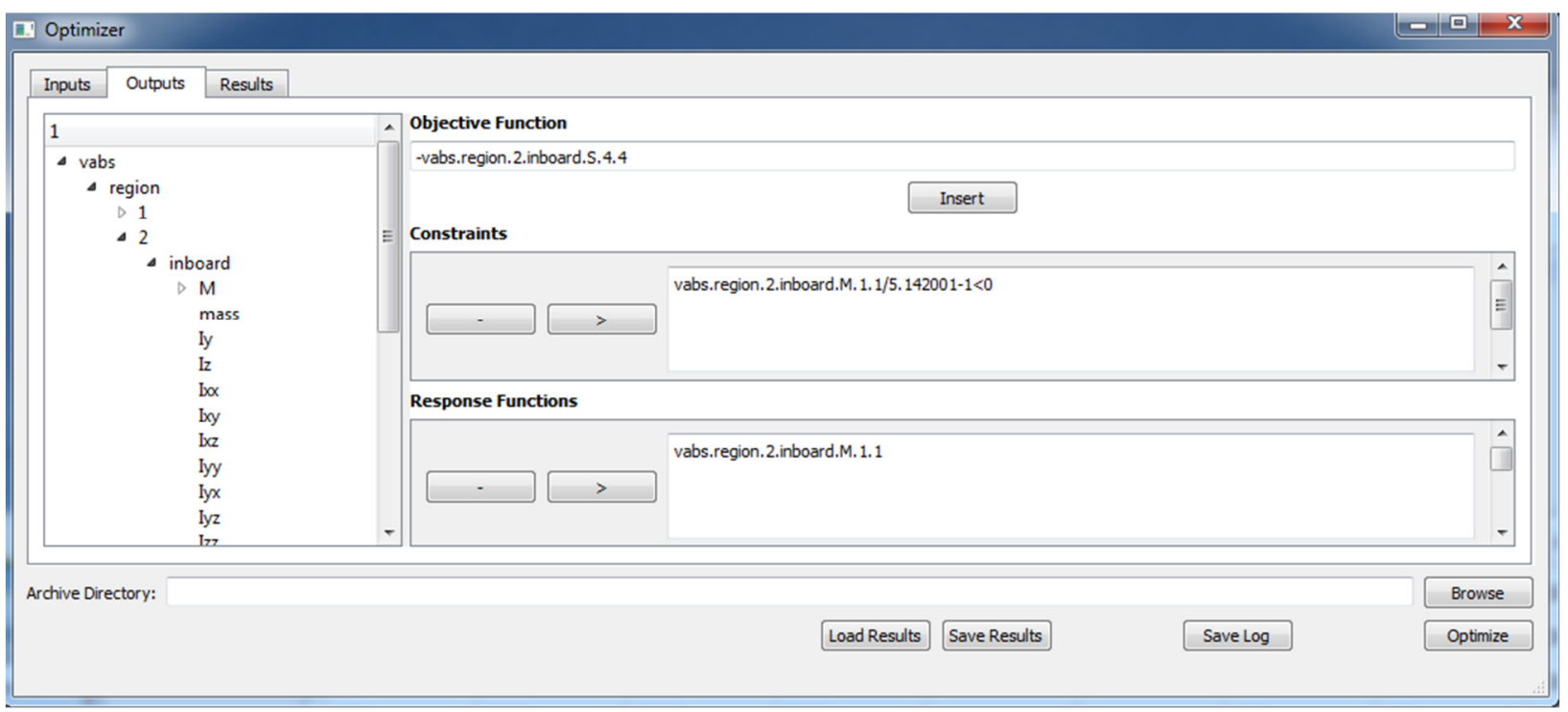

Figure 7. Optimization Interface (Outputs). 


\section{Application Example: Vibratory Hub Load Minimization}

The MDO framework described in this paper can be used to solve a variety of optimization and design problems involving metallic and composite rotor blades. In order to demonstrate the capabilities of the design framework, an existing wind-tunnel model composite rotor blade was selected as the baseline rotor design.

The loosely coupled design environment based on ModelCenter, shown in Figure 8, was used for these studies because at the time the studies were done, the DAKOTA integration had not been developed yet. The components forming part of the design loop start with the "Run_Counter" component and end with the "Run_Driver", both of which perform housekeeping functions. The next to last component, "Archive", archives all files generated by the process. The actual components that perform blade design functions start with the "Cross_Section_Generator" component, which executes IXGEN (which, in turn, executes UM/VABS for every cross section), and UM/VABS post-processing, which applies ballast masses to the cross section and performs unit conversion between IXGEN and RCAS from SI to British if desired. The next component, "RCAS", runs RCAS, as the name implies. "Stress_Strain_Recovery" uses the stress/strain influence coefficient matrices produced by UM/VABS and the element forces/moments produced by RCAS and processes them to recover the cross-sectional stress and strain distribution for each cross section. A flag in the input for the recovery component controls the generation of Tecplot files for each stress and strain component for each cross section for further manual post-processing.

This implementation of the rotor blade design process in ModelCenter facilitates a wide variety of trade study and optimization scenarios. Any parameter exposed in ModelCenter can be used as a design variable, part of a response, constraint or objective function. Design drivers can be wrapped around the entire process, or individual components of it, such as IXGEN-UM/VABS-VABS Post-Processing to optimize the structural properties of an individual cross section without running the aeromechanical analysis, as demonstrated in reference 6.

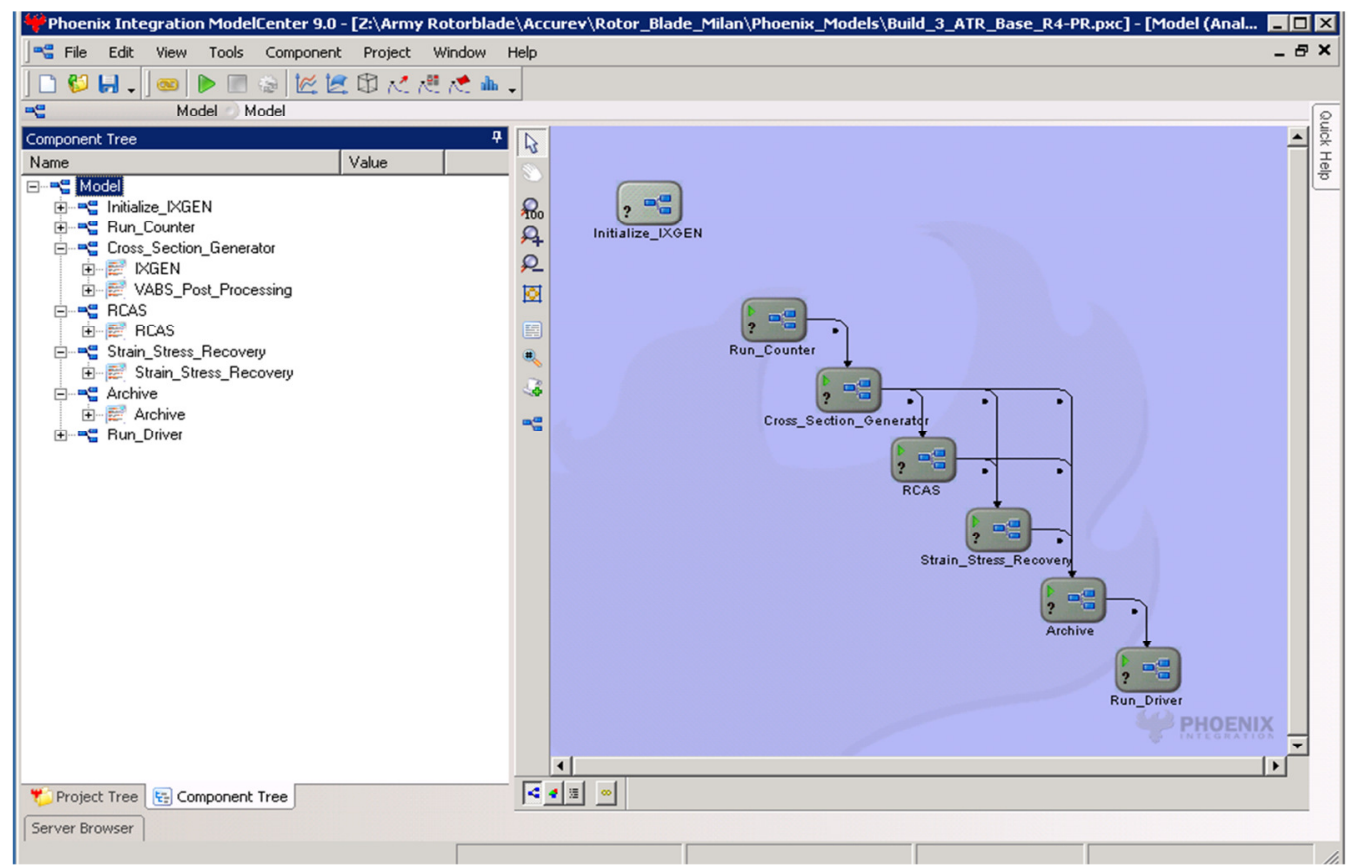

Figure 8. ModelCenter-Based Blade Optimization Process.

\section{A. Description of baseline rotor blade}

The NASA/Army/MIT Active Twist Rotor (ATR) ${ }^{10,11}$ was originally designed to study the effects of twist actuation on vibration and noise reduction, and performance improvement in rotor blades. The 9-ft-diameter fourbladed rotor was tested at NASA LaRC's Transonic Dynamics Tunnel and was the first-of-a-kind system to demonstrate vibration reduction using embedded active fiber composites (AFC) in a closed loop ${ }^{12}$. For the current study, the active twist of the blade is not considered and the AFC plies used in the cross section layup are treated as another passive material. This particular rotor blade was chosen for its known properties and available experimental and computational results. Figure 9 shows the planform view of the blade and its corresponding dimensions. 


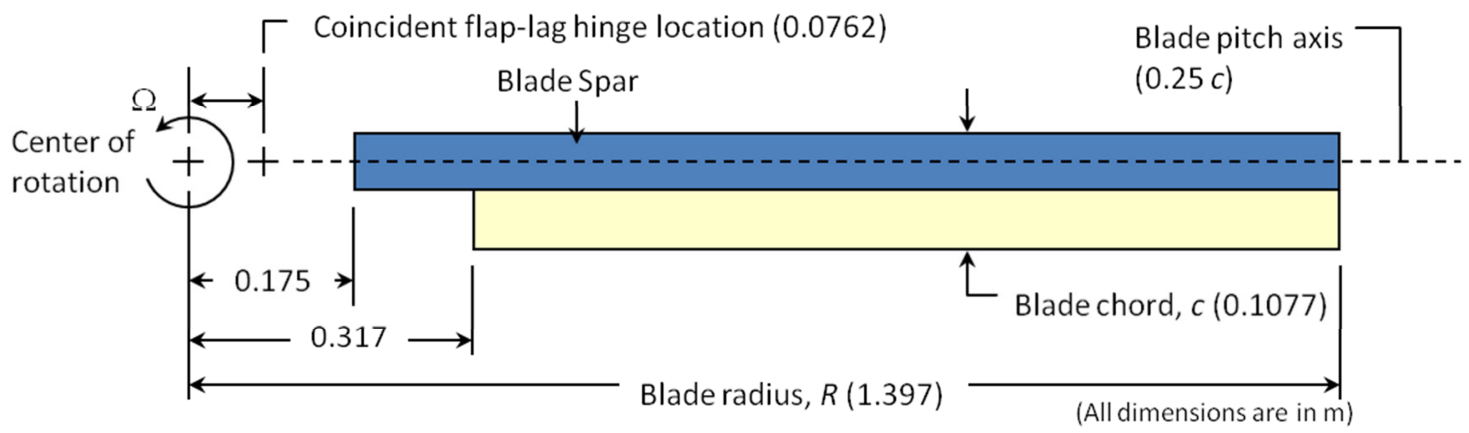

Figure 9. Planform View of the ATR Rotor Blade (Dimensions in Meters).

The airfoil for this blade is the NACA 0012 and it is uniform along the blade radius. The reference crosssectional layup is shown in Figure 10, while Table 1 lists the ply angle for all the plies used in the cross section of the rotor blade. Among the plies used, E-Glass is bidirectional while S-glass and AFC plies are unidirectional. The specific material properties can be found in Table 2 .

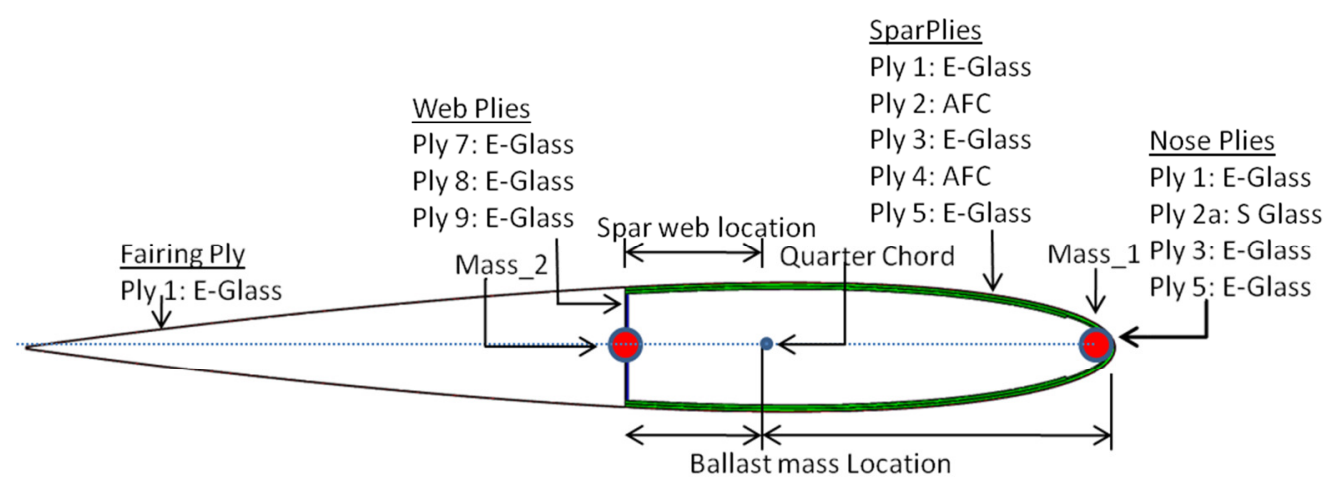

Figure 10. Cross-Sectional Shape of the Rotor Blade (NACA 0012 Airfoil).

Table 1. Ply Angles.

Table 2. Material Properties.

\begin{tabular}{|c|c|}
\hline Ply Name & Angle \\
\hline Ply 1 & $0 / 90$ \\
Ply 2 & +45 \\
Ply 2a & 0 \\
Ply 3 & $0 / 90$ \\
Ply 4 & -45 \\
Ply 5 & $0 / 90$ \\
Ply 6 & $0 / 90$ \\
Ply 7 & $0 / 90$ \\
Ply 8 & $0 / 90$ \\
\hline
\end{tabular}

\begin{tabular}{|c|c|c|c|}
\hline & E-Glass & S-Glass & AFC \\
\hline Thickness $(\mu \mathrm{m})$ & 114.3 & 230 & 200 \\
Density $\left(\mathrm{kg} / \mathrm{m}^{3}\right)$ & 1720 & 1860 & 4060 \\
$\mathrm{E}_{11}(\mathrm{GPa})$ & 20.7 & 43.4 & 30.2 \\
$\mathrm{E}_{22}(\mathrm{GPa})$ & 20.7 & 12 & 14.9 \\
$\mathrm{E}_{33}(\mathrm{GPa})$ & 20.7 & 12 & 14.9 \\
$\mathrm{G}_{12}(\mathrm{GPa})$ & 4.1 & 3.6 & 5.13 \\
$\mathrm{G}_{13}(\mathrm{GPa})$ & 4.1 & 3.6 & 5.13 \\
$\mathrm{G}_{23}(\mathrm{GPa})$ & 4.1 & 3.6 & 5.13 \\
$v_{12}$ & 0.13 & 0.28 & 0.454 \\
$v_{13}$ & 0.13 & 0.28 & 0.454 \\
$v_{23}$ & 0.3 & 0.3 & 0.3 \\
\hline
\end{tabular}

The characteristic properties of the baseline ATR blade and its structural frequencies at 100\% RPM are listed in Table 3. Blade frequencies were obtained using RCAS. For the example results presented here, an advance ratio of 0.24 is used to avoid the effects of dynamic stall. 
Table 3. Characteristics of the Rotor Blade.

\begin{tabular}{|c|c|c|c|}
\hline Rotor Type & Fully Articulated & Mode Shape & Frequencies (/rev) \\
\hline Number of blades & 4 & $1^{\text {st }}$ chordwise bending & 0.29 \\
\hline Blade radius ( $\mathrm{R}$ ) & $1.397 \mathrm{~m}$ & $1^{\text {st }}$ flapwise bending & 1.04 \\
\hline Blade Chord (c ) & $0.1077 \mathrm{~m}$ & $2^{\text {nd }}$ flapwise bending & 2.76 \\
\hline Airfoil Section & NACA 0012 & $3^{\text {rd }}$ flapwise bending & 5.29 \\
\hline Blade Pretwist & $-10 \mathrm{deg}$ & $2^{\text {nd }}$ chordwise bending & 5.75 \\
\hline Hinge Offset & $0.0762 \mathrm{~m}$ & $1^{\text {st }}$ torsion & 6.74 \\
\hline Rotor Speed & 687.5 RPM & & \\
\hline $\mathrm{C}_{\mathrm{T}}$ & 0.0066 & & \\
\hline Air density & $2.42 \mathrm{~kg} / \mathrm{m}^{3}$ & & \\
\hline Advance ratio $(\mu)$ & 0.24 & & \\
\hline
\end{tabular}

For the rotor dynamic analysis, the trim

Table 4. Hub Loads for the Baseline Case at $\boldsymbol{\mu}=0.24$ option is included in the RCAS model. The trim targets used in the analysis are: $\mathrm{C}_{\mathrm{T}}=$ 0.0066 , no cyclic moments $\left(\mathrm{M}_{\mathrm{x}}=0\right.$ and $\mathrm{M}_{\mathrm{y}}$ $=0$ ), and the blade pitch settings are used as the trim variables. The mean value of the hub loads and the amplitude of the 4/rev component for the baseline blade are given in Table 4 , where $F_{x}, F_{y}$ and $F_{z}$ represent components of the hub force in the nonrotating frame, while $\mathrm{M}_{\mathrm{x}}, \mathrm{M}_{\mathrm{y}}$ and $\mathrm{M}_{\mathrm{z}}$ represent components of the moments at the

\begin{tabular}{|c|c|c|}
\hline & Mean Values & 4/rev Amplitude \\
\hline $\mathrm{F}_{\mathrm{x}}(\mathrm{N})$ & 8.85 & 1.38 \\
$\mathrm{~F}_{\mathrm{y}}(\mathrm{N})$ & 13.91 & 2.04 \\
$\mathrm{~F}_{\mathrm{z}}(\mathrm{N})$ & 990.77 & 23.56 \\
$\mathrm{M}_{\mathrm{x}}(\mathrm{Nm})$ & 0.44 & 40.52 \\
$\mathrm{M}_{\mathrm{y}}(\mathrm{Nm})$ & 1.19 & 36.24 \\
$\mathrm{M}_{\mathrm{z}}(\mathrm{Nm})$ & 47.41 & 1.06 \\
\hline
\end{tabular}
hub.

\section{B. Definition of the Rotor Blade Optimization Problem}

A different set of objective functions can be defined depending upon the problem being solved. In principle, any output provided by RCAS or by UM/VABS can be selected as the objective function. For this paper, minimization of vertical $4 / \mathrm{rev}$ vibratory load at the hub is considered as the objective function.

Similarly, any combination of outputs from RCAS and UM/VABS can be used to form constraints. For the optimization studies presented herein, the following set of parameters will be constrained:

a) Chordwise location of blade cross-sectional center of gravity.

b) Chordwise location of cross-sectional shear center.

c) Blade fundamental rotating frequencies.

d) Maximum allowable blade strain in the cross section.

e) Mass per unit length for the blade cross section.

For the purpose of solving the optimization problem, gradient based or non-gradient based methods like a genetic algorithm or surrogate optimization can be used depending upon the nature of the problem being solved. Finally, the design variables that can be used for optimization are:

- The thickness and lamination angle of each ply in the cross section layup. However, the material properties used in each ply are kept constant.

- The chordwise location of the vertical spar web.

- Two discrete ballast masses and their chordwise locations

- Blade tip sweep angle $\Lambda$ (as shown in Figure 11) and blade pre-twist (not used for the cases shown in this paper) 
As described in the earlier section, the blade span can be divided into different sections depending upon the complexity of rotor blade in terms of its geometric shape or variation in material properties. The cross-sectional variables are defined independently for each section and they can be used as design variables. In the current analysis, the blade is subdivided into two sections as shown in Figure 12, where section 1

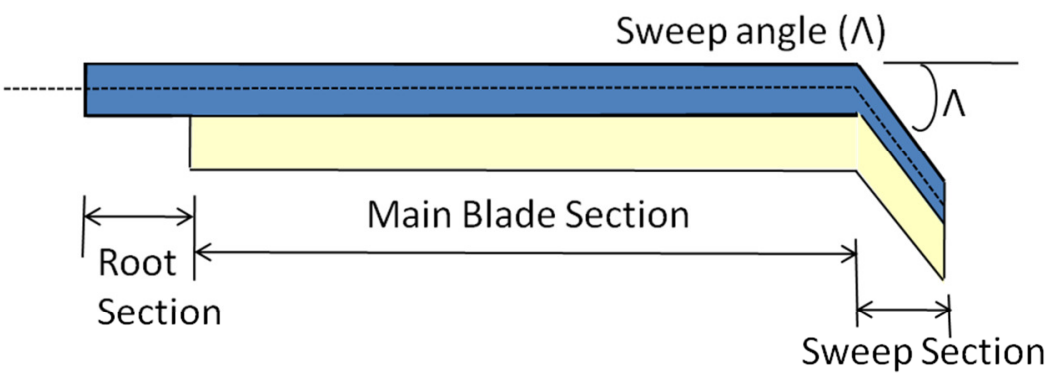
represents the blade root (that allows a different shape than the NACA 0012) and section 2 represents the rest of the blade with uniform properties.

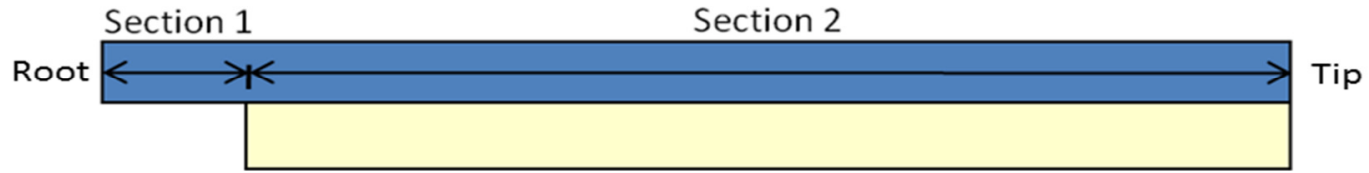

Figure 12. Blade Sub-Divisions for Design Variable Groups.

From the above discussion it can be seen that a large number of variables can be used as design variables. However, since each run for a complete rotor analysis takes between 15 and 30 minutes in a Windows machine (Intel Core2 QUAD CPU @ 2.39GHz and 1.96GB of RAM), and the number of runs required for optimization increases exponentially with the number of design variables, it is desirable to reduce the number of design variables to the most influential ones. The variables which are most critical for the design can be identified through parametric studies.

\section{Optimization Results}

i) Minimizing FZ4 with 13 design variables

In the first optimization study, the amplitude of the $4 / \mathrm{rev}$ vertical hub force (FZ4) is used as the objective function which is minimized. Design variables used for this study are ply angles and ply thickness for Ply 1 to Ply 5, location of the spar web and mass and location of the forward ballast mass in section 2 . The cross-sectional properties of section 1 are kept constant during the optimization process. Upper and lower limits for these design variables are listed in Table 5. The lower limit used for ply thickness corresponds to $1 / 4^{\text {th }}$ of the baseline ply thickness while upper limit for the ply thickness corresponds to four times the baseline value. Upper and lower limit used for ply angles depend upon the
Table 5. Design Variables for Minimization of FZ4.

\begin{tabular}{|c|c|cc|}
\hline Design variables & Baseline & Min & Max \\
\hline Thickness Ply 1 $(\mu \mathrm{m})$ & 110 & 28.6 & 460 \\
Thickness Ply 2 $(\mu \mathrm{m})$ & 200 & 50.8 & 810 \\
Thickness Ply 3 $(\mu \mathrm{m})$ & 110 & 28.5 & 460 \\
Thickness Ply 4 $(\mu \mathrm{m})$ & 200 & 50.8 & 810 \\
Thickness Ply 5 $(\mu \mathrm{m})$ & 110 & 28.6 & 460 \\
Angle Ply 1 $(\mathrm{deg})$ & 0 & -45 & 45 \\
Angle Ply 2 $(\mathrm{deg})$ & -45 & -90 & 90 \\
Angle Ply 3 $(\mathrm{deg})$ & 0 & -45 & 45 \\
Angle Ply 4 $(\mathrm{deg})$ & 45 & -90 & 90 \\
Angle Ply 5 $(\mathrm{deg})$ & 0 & -45 & 45 \\
Spar Web Loc $(\% \mathrm{c})$ & 37.5 & 15.0 & 75.0 \\
Ballast mass $(\mathrm{kg} / \mathrm{m})$ & 0.1326 & 0.05 & 0.25 \\
Ballast mass Loc $(\% \mathrm{c})$ & 0 & 0 & 25 \\
\hline
\end{tabular}


nature of the material, whether it is unidirectional or bidirectional. The range used for the forward ballast mass is 0.05 to $0.25 \mathrm{~kg} / \mathrm{m}$, and its location is allowed to vary between the leading edge and the quarter chord of the airfoil section. Constraints used during the optimization are listed in Table 6. Shear Center (SC) and CG of the cross section are constrained to lie near the quarter chord of the airfoil to indirectly enforce stability criteria. Mass of the cross section is allowed to vary $\pm 15 \%$ off the baseline value. Maximum allowable axial and shear strain in the cross section is limited to 5000 microstrain. And the $1^{\text {st }}$ torsion frequency is constrained between $5 / \mathrm{rev}$ and $8 / \mathrm{rev}$.

For this optimization, the complete rotor blade analysis process is executed at each step which involves running IXGEN, UM/VABS and RCAS. During the parametric studies, it was observed that some of the cases in RCAS do not reach a converged solution for trim analysis and hence, there were a few failed cases involved. For the gradient based optimization, it is required that none of the cases fail. And hence, the gradient based algorithm was not used for this optimization. (As a future improvement of the environment, one could catch failures of the analysis codes involved and set a constraint to "violated" in the case of failure. This way, a gradient-based optimizer will avoid this region of the design space). Among the various options available in the ModelCenter Release 10 optimization tool package, "Nondominated Sorting Genetic Algorithm II (NSGA)" was used since it allowed for failed runs in the optimization process. Parameters used for NSGA optimization are listed in Table 7.

The optimization process ran for approximately 50 hours and stopped after exceeding the limit on maximum number of generations allowed. During this time, a total of 288 iterations were performed. The final optimized result obtained at the end shows almost $47.5 \%$ reduction in FZ4. Details for the optimized case are listed in Table 8. Variation of the objective function, design variables and constraints with generation are shown in Figure 13 to Figure 16. The optimized design corresponding to maximum FZ4 reduction has the following characteristics:
a) Increase in thickness of high density AFC plies.
b) Very small variation in ply angle from the baseline case, except for Ply 1.
c) Increase in cross-sectional mass per unit length and torsion frequency.
d) Very small increase in maximum blade strains.
e) Small variation in location of cross-sectional CG and shear center.

The objective function shown in Figure 13 indicates a steady improvement in the result as the number of generation increases. However, not all the generations provide improvement over the previous one and for those ones, results are not included. Note that the results obtained at the end of the first two generations are the same as the baseline results. Variation of ply thickness shown in Figure 14 indicates that AFC plies get thicker as the optimization progresses while a very small increase in ply thickness is observed for E-Glass plies. The increase in cross-sectional mass and stiffness due to an increase in thickness of more dense plies leads to lower FZ4. Ply angles for Ply 3 and Ply 5 do not vary much during the optimization as shown in Figure 14. However, ply angle for Ply 4 becomes slightly more positive and ply angle for Ply 5 becomes slightly more negative. This is accompanied by an increase in 
ply angle of bi-directional Ply 1 by 30 degrees. The final effect of these changes is higher torsion frequency without significant variation in other modes which results in smaller FZ4.

The chordwise location of ballast mass and spar web do not vary much during the optimization, as shown in Figure 15. However, there is a steady increase in ballast mass added which causes the blade's crosssectional mass per unit length to increase and $\mathrm{CG}$ to move closer to the leading edge. During the parametric study with the ballast mass, it was observed that both these trends are favorable for minimizing FZ4. The nondimensionalized values of the constraints for all the generations are shown in Figure 16. The constraints are nondimensionalized using their maximum and minimum values such that " 0 " represents the minimum value of the constraint while " 1 " represents the maximum value of the constraints. As discussed previously, $\mathrm{M}_{11}$ and the first torsion frequency increase during the optimization. The shear center and CG of the cross section move slightly forward.
Table 8. Details of the Optimized Design.

\begin{tabular}{|c|cc|c|}
\hline Objective Function & Baseline & Optimized & \% Reduction \\
\hline FZ4 $(\mathrm{N})$ & 23.56 & 12.38 & 47.45 \\
\hline
\end{tabular}

\begin{tabular}{|c|c|c|}
\hline Design variables & Baseline & Optimized \\
\hline Thickness Ply 1 $(\mu \mathrm{m})$ & 110.0 & 123.0 \\
Thickness Ply 2 $(\mu \mathrm{m})$ & 200.0 & 288.7 \\
Thickness Ply 3 $(\mu \mathrm{m})$ & 110.0 & 113.5 \\
Thickness Ply 4 $(\mu \mathrm{m})$ & 200.0 & 286.8 \\
Thickness Ply 5 $(\mu \mathrm{m})$ & 110.0 & 120.3 \\
Angle Ply 1 $(\mathrm{deg})$ & 0.00 & 30.03 \\
Angle Ply 2 $(\mathrm{deg})$ & -45.00 & -57.77 \\
Angle Ply 3 $(\mathrm{deg})$ & 0.00 & -0.06 \\
Angle Ply 4 $(\mathrm{deg})$ & 45.00 & 51.14 \\
Angle Ply 5 $(\mathrm{deg})$ & 0.00 & 1.01 \\
Spar Web Loc $(\% \mathrm{c})$ & 37.5 & 37.4 \\
Ballast mass $(\mathrm{kg} / \mathrm{m})$ & 0.1326 & 0.1616 \\
Ballast mass Loc $(\% \mathrm{c})$ & 0 & 0 \\
\hline
\end{tabular}

\begin{tabular}{|c|c|c|}
\hline Constraints & Baseline & Optimized \\
\hline CG loc $(\% \mathrm{c})$ & 26.19 & 24.87 \\
SC Loc $(\% \mathrm{c})$ & 21.64 & 20.41 \\
$\mathrm{M}_{11}(\mathrm{~kg} / \mathrm{m})$ & 0.637 & 0.718 \\
$\varepsilon_{11} \max (\mu \varepsilon)$ & 2847 & 2864 \\
$\varepsilon_{12} \max (\mu \varepsilon)$ & 3678 & 3808 \\
Tor freq $(/ \mathrm{rev})$ & 6.74 & 7.21 \\
\hline
\end{tabular}

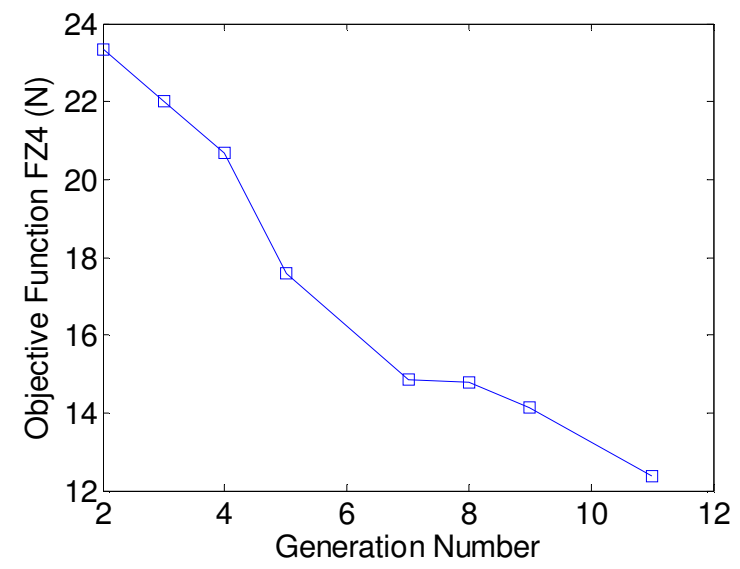

Figure 13. Variation of Objective Function with Generation. 

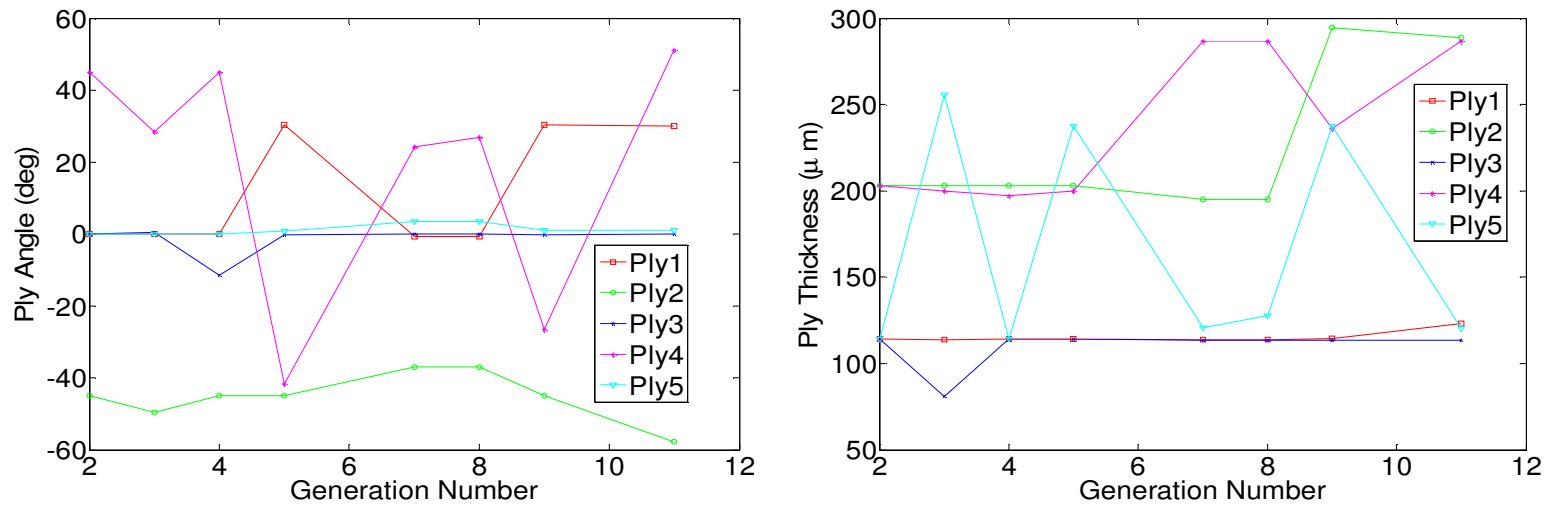

Figure 14. Variation of Ply Thickness and Angles with Generation.
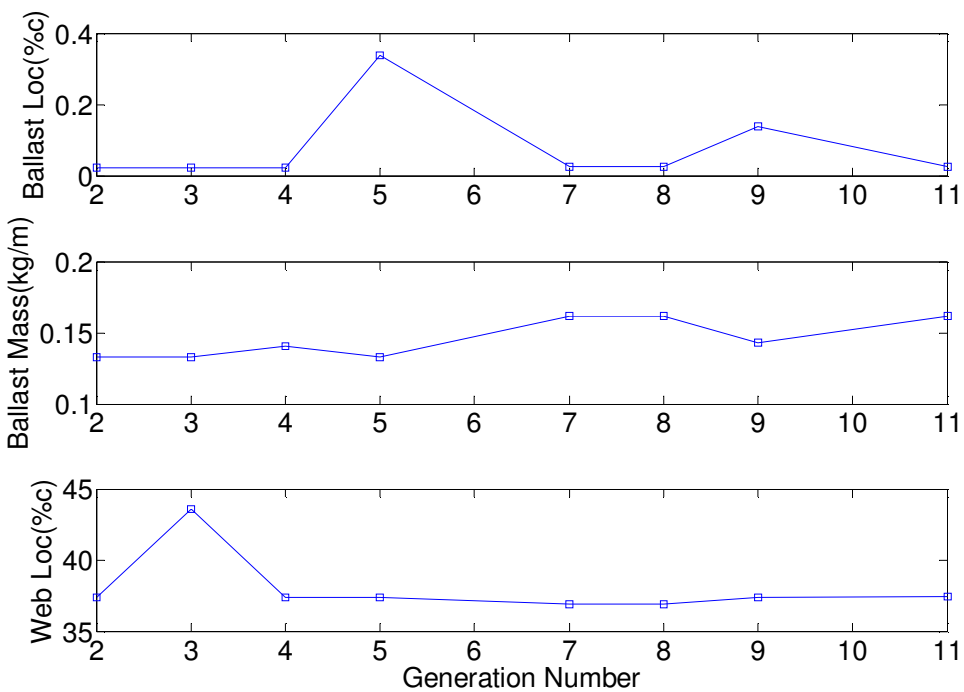

Figure 15. Variation of Ballast Mass, Location and Spar Web Location with Generation.

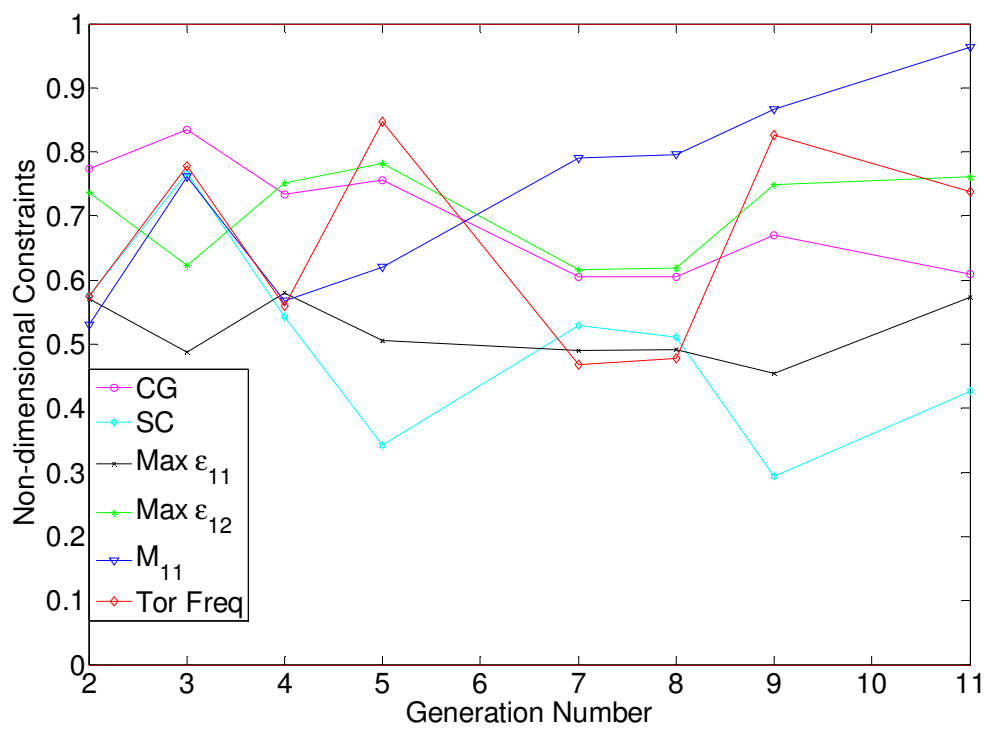

Figure 16. Variation of Constraints with Generation.

13

American Institute of Aeronautics and Astronautics 


\section{ii) Minimizing FZ4 with 8 design variables}

In this case, only 8 design variables are considered instead of 13 design variables used in the previous study. The ply angles are not considered here as the design variables since it was observed that the value of ply angles did not vary significantly during the optimization process. The optimization parameters and bounds of the rest of the design variables are unchanged from the previous optimization. As in the earlier study, the optimization stopped after exceeding the limit on maximum number of generations allowed, which was fixed at 12 . Final results obtained and differences with the baseline case are given in Table 9.

Table 9. Design Variables and Constraints for the Optimized Case.

\begin{tabular}{|c|c|c|c|c|c|}
\hline \multirow[t]{2}{*}{ Design variables } & \multirow[t]{2}{*}{ Baseline } & \multicolumn{2}{|c|}{ Set 1: With 13 D.V. } & \multicolumn{2}{|c|}{ Set 2: With 8 D.V. } \\
\hline & & Actual Val & Difference & Actual Val & Difference \\
\hline Thickness Ply 1 ( $\mu \mathrm{m})$ & 110 & 123 & 13 & 76.4 & -33.6 \\
\hline Thickness Ply $2(\mu \mathrm{m})$ & 200 & 288.7 & 88.7 & 475.3 & 275.3 \\
\hline Thickness Ply $3(\mu \mathrm{m})$ & 110 & 113.5 & 3.5 & 109.9 & -0.1 \\
\hline Thickness Ply 4 ( $\mu \mathrm{m})$ & 200 & 286.8 & 86.8 & 180.6 & -19.4 \\
\hline Thickness Ply $5(\mu \mathrm{m})$ & 110 & 120.3 & 10.3 & 172.5 & 62.5 \\
\hline Angle Ply 1 (deg) & 0 & 30.03 & 30.03 & 0 & 0 \\
\hline Angle Ply 2 (deg) & -45 & -57.77 & -12.77 & -45 & 0 \\
\hline Angle Ply 3 (deg) & 0 & -0.06 & -0.06 & 0 & 0 \\
\hline Angle Ply 4 (deg) & 45 & 51.14 & 6.14 & 45 & 0 \\
\hline Angle Ply 5 (deg) & 0 & 1.01 & 1.01 & 0 & 0 \\
\hline Spar Web Loc (\%c) & 37.5 & 37.417 & -0.083 & 31.66 & -5.84 \\
\hline Ballast mass $(\mathrm{kg} / \mathrm{m})$ & 0.1326 & 0.1616 & 0.029 & 0.1605 & 0.0279 \\
\hline Ballast mass Loc $(\% \mathrm{c})$ & 0 & 0 & 0 & 1.6 & 1.6 \\
\hline \multicolumn{6}{|l|}{ Constraints } \\
\hline CG loc $(\% c)$ & 26.19 & 24.87 & -1.32 & 23.86 & -2.33 \\
\hline SC Loc (\%c) & 21.64 & 20.41 & -1.23 & 17.16 & -4.48 \\
\hline $\mathrm{M}_{11}(\mathrm{~kg} / \mathrm{m})$ & 0.637 & 0.718 & 0.081 & 0.692 & 0.055 \\
\hline$\varepsilon_{11} \max (\mu \varepsilon)$ & 2847 & 2864 & 17 & 4103.3 & 1256.3 \\
\hline$\varepsilon_{12} \max (\mu \varepsilon)$ & 3678 & 3808 & 130 & 3682.1 & 4.1 \\
\hline Tor freq (/rev) & 6.74 & 7.21 & 0.47 & 6.3 & -0.44 \\
\hline \multicolumn{6}{|l|}{ Objective Function } \\
\hline FZ4 & 23.5 & 12.86 & -10.64 & 10.887 & -12.613 \\
\hline
\end{tabular}

The results obtained show that the vibration reduction obtained using eight design variables is more than that obtained using thirteen design variables. Due to smaller number of the design variables, the optimizer is able to explore the design space better in Set 2. The trend observed in Set 2 for the design variables is different than that observed in case on Set 1. A significant increase is observed in the thickness of Ply 2 in Set 2 which causes an increase in the cross-sectional mass. The decrease in the thickness of Ply 1, which wraps around the whole airfoil, results in forward motion of the center of gravity for the cross section. Also, the vertical spar web has moved forward which caused the shear center of the cross section to move forward, too. It was observed during the parametric studies that, as the cross-sectional mass increases and the CG of the cross section moves forward, the amplitudes of the vibratory loads decrease. There is a small increase in the maximum strains observed in the cross section since Ply 1 has become thinner. However, the maximum strains obtained for the cross section are still within the allowable limits. There is a small decrease in the torsional frequency due to the reduction in the torsional stiffness caused by the shift of the vertical spar web towards the leading edge. This indicates that the amplitude of 
vibratory loads is very sensitive to the cross-sectional mass and its CG location. Thus, in the case of genetic optimization, a reduction in the number of design variables may lead to better results when the total number of generations allowed is fixed since it helps in better exploration of the design space.

\section{Conclusion}

A powerful, easy to use design environment has been developed to support conceptual and preliminary rotor blade design. It integrates several well-established analysis codes from different sources: UM/VABS for cross sectional analysis, RCAS for rotorcraft simulation and both DAKOTA and Phoenix ModelCenter for optimization. It is driven by IXGEN, a graphical feature-based modeling tool for rotor blades and slender wings. This tool is an enabler for conceptual/early preliminary multidisciplinary rotor blade design, allowing rapid design trade studies early in the design process with realistic structural properties for modern composite rotor blades. The tool supports multiple design scenarios. It can be used in a cross-section-focused structural design problem in which one might want to find a feasible structural concept and layup resulting in particular blade stiffness and mass properties or location of the elastic axis. It can also be used in a more comprehensive multidisciplinary environment including a full rotorcraft aeromechanical analysis, where the entire rotor system can be optimized with respect to objectives such as rotor performance, vibratory loads, noise etc. subject to aeroelastic and dynamic stability and other design constraint.

The design environment was successfully used to perform detailed parametric and optimization studies on a scaled composite rotor blade. The cross-sectional design variables which can be easily modified during the composite rotor blade manufacturing process were used as the design variables. The objective function used in the optimization study was minimization of $4 / \mathrm{rev}$ vertical force at the rotor hub, which required complete aeromechanic analysis of the rotor blade for each iteration. The final results obtained from these studies showed almost 50\% reduction in vertical 4/rev vibratory load at the hub while satisfying the constraints on blade cross-sectional and dynamic properties.

\section{Acknowledgments}

This work was sponsored by the US Army Research, Development and Engineering Command (AMRDEC), Aviation Applied Technology Directorate (AATD) through SBIR Phase II contract \# W911W6-10-C-0030.

\section{References}

1. Palacios, R. and Cesnik, C. E. S., "Cross-Sectional Analysis of Non-Homogeneous Anisotropic Active Slender Structures," AIAA Journal, Vol. 43, No. 12, 2005, pp. 2624-2638

2. Palacios, R. and Cesnik, C. E. S., "A Geometrically-Nonlinear Theory of Composite Beams with Deformable Cross Sections," AIAA Journal, Vol. 46, No. 2, February 2008

3. RCAS User's Manual, Version 2.0, US Army Aviation and Missile Command, Moffett Field, CA

4. Cesnik, C. E. S. and Hodges, D. H., "VABS: A New Concept for Composite Rotor Blade Cross-Sectional Modeling," Journal of the American Helicopter Society, Vol. 42, No. 1, 1997, pp. 27-38

5. Cesnik, C. E. S., Mok, J., Morillo, J. A., and Parikh, A., "Design Optimization of Active Twist Rotor Blades," $30^{\text {th }}$ European Rotorcraft Forum, Marseille, France, September 16-18, 2004

6. Rohl, P. J., Dorman, P., Cesnik, C. E. S., Kumar, D., "IXGEN - A Modeling Tool for the Preliminary Design of Composite Rotor Blades", AHS Future Vertical Lift Aircraft Design Conference, San Francisco, CA, January $18-20,2012$

7. Open Cascade 6.1 User and Developer Documentation, www.opencascade.org, 2010

8. DAKOTA Version 5.0 User's Manual, Sandia National Laboratories, P.O. Box 969, Livermore, CA 94551, May 2010

9. ModelCenter Version 10.0, Phoenix Integration, 2011

10. Cesnik, C. E. S., Shin, S., Wilkie, W. K., Wilbur, M. L. and Mirick, P. H., "Modeling, Design and Testing of the NASA/ARMY/MIT Active Twist Rotor Prototype Blade." American Helicopter Society 55th Annual Forum Montreal, Canada, May 25-27, 1999.

11. Cesnik, C. E. S., Shin, S. and Wilbur, M. L., "Dynamic Response of Active Twist Rotor Blades." Smart Materials and Structures, Vol. 10, 2001, pp. 62-76.

12. Shin, S. J., Cesnik, C. E. S., and Hall, S. R., "Closed-loop Control Test of the NASA/Army/MIT Active Twist Rotor for Vibration Reduction," Journal of the American Helicopter Society, Vol. 50, No. 2, 2005, pp. 178-194. 